\title{
Protective effect of Jageum-Jung on chlorpyrifos-induced acute toxicity in ICR mice
}

\author{
Nam-Hui Yim ${ }^{1}$ (D) Jin Yeul Ma $^{1}$
}

Received: 4 September 2018 / Accepted: 15 November 2018 / Published Online: 31 December 2018

(C) The Korean Society for Applied Biological Chemistry 2018

\begin{abstract}
Chlorpyrifos (CPF) is one of the most heavily used organophosphate pesticides and is useful as an insecticide drug. However, CPF also causes toxic effects in nontarget organisms, including humans and animals. Jageum-Jung (JGJ) is a traditional oriental medicine, composed of five specific herbs with antioxidant and hepatoprotective properties, used for detoxification. In the present study, highly concentrated CPF was orally administrated to male Institute of Cancer Research mice to produce acute toxicity, and the protective effects of JGJ administration were investigated through statistical analysis of changes in body and organ weights and serum biochemical parameters. JGJ caused body and organ weights to recover and reduced the levels of serum biochemical parameters indicative of liver damage, such as glutamic oxalate transaminase, glutamic pyruvate transaminase, alkaline phosphatase, lactic dehydrogenase, urea, glucose, total cholesterol, and triglyceride, that had been increased by CPF treatment. Our results demonstrated that JGJ ameliorates the effects of acute chlorpyrifos-induced toxicity. Therefore, JGJ has the potential to be used as a traditional medicine to alleviate insecticide toxicity.
\end{abstract}

Keywords Acute toxicity $\cdot$ Biochemical parameters $\cdot$ Chlorpyrifos - Hepatoprotective effect · Jageum-Jung

Jin Yeul Ma $(\bowtie)$

E-mail: jyma@kiom.re.kr

${ }^{1}$ Korean Medicine (KM)-Application Center, Korea Institute of Oriental Medicine (KIOM), Daegu 701-300, Republic of Korea

This is an Open Access article distributed under the terms of the Creative Commons Attribution Non-Commercial License (http://creativecommons. org/licenses/by-nc/3.0/) which permits unrestricted non-commercial use, distribution, and reproduction in any medium, provided the original work is properly cited.

\section{Introduction}

Chlorpyrifos (O,O-diethyl-O-(3,5,6-trichloro-2-pyridyl) phosphorothioate, $\mathrm{CPF})$ is a broad spectrum organophosphate pesticide which is used in domestic and industrial applications all over the world [1,2]. CPF is known to inhibit acetylcholinesterase activity, which results in the accumulation of acetylcholine at cholinergic synapses [3]. CPF also affects other systems, including the liver [4], kidneys [5], lungs [6], brain [2], and erythrocytes [7], which elicits associated toxic effects, such as hepatic dysfunction [8], hematological and immunological abnormalities [9], and neurotoxicity and neurobehavioral changes [10].

Herbal medicines target multiple cellular pathways to counteract impaired cellular function dysregulated due to a variety of causes, such as infection and toxicosis [11]. However, herbal remedies have yet to be fully integrated into mainstream medicine due to a lack of experimental and clinical studies of their safety, efficacy, and underlying pharmacological mechanisms [12]. Therefore, multi-herbal cocktails must be pre-clinically evaluated to accurately compare traditional herbal medicines with modern therapeutics. The traditional oriental medicine Jageum-Jung (JGJ) is a mixture of five herbs, including Galla Rhois, Cremastrae Tuber, Euphorbiae Pekinensis Radix, Euphorbiae Lathyridis Semen, and Muschus, which has been used for detoxification and for treating cancer and inflammatory diseases in Korea, China, and Japan [13]. Recent evidence indicates that the JGJ has the anti-cancer effects through inducing the apoptosis and cell cycle arrest in HepG2 human hepatocytes [14]. Furthermore, in our previous study, JGJ improved atopic dermatitis (AD)-like skin lesions in 2,4-dinitrochlorobenzene (DNCB)-treated mice and inhibited degranulation of mast cell [15].

This study aimed to examine CPF toxicity and the protective effect of JGJ against CPF based on their effects on relative organ weights and serum biochemical parameters. 


\section{Materials and Methods}

\section{Preparation of chemicals and JGJ}

For oral administration in mice, chlorpyrifos (CPF) and corn-oil were purchased from Sigma-Aldrich. (St. Louis, MO, USA). JGJ was obtained from Cheung-sin herbal medicine pharmacy (Daegu, Korea). JGJ was composed of five herbs and prepared with reference to 'DongUiBoGam' and 'BangYakHapPyun'. The herbal constitution ratio of JGJ are listed in Table 1.

\section{Animal care and treatment}

Male Institute of Cancer Research (ICR) mice were purchased to five-week-old widely used in toxicological studies from Samtako BioKorea (Osan, Korea). After acclimatization for a week, mice were randomly divided into control group (vehicle), CPF-treated group, JGJ-treated group, and CPF and JGJ co-treated group (10 mice of each group). CPF was dissolved in corn-oil, and JGJ powder was dissolved in saline, which was orally administrated to mice. For control groups, corn-oil and saline were orally administrated with same volume of CPF solution and JGJ solution, respectively. Animal treatment schedule was shown in Figure 1A. For a period of 2 days to evaluate the acute toxicity of $\mathrm{CPF}$, mice received the specific dose of CPF in corn-oil $(150 \mu \mathrm{L})$. CPF was first exposured, and JGJ was treated thirty minuites later as a post-treatment of JGJ. Only JGJ-treated group was administrated with corn-oil (150 $\mu \mathrm{L})$ at first exposured step and administrated with $200 \mathrm{mg} / \mathrm{kg}$ at post-treatment step. All groups were maintained under standard conditions of temperature $\left(22.5 \pm 0.5{ }^{\circ} \mathrm{C}\right)$, humidity $(42.6 \% \pm 1.7 \%)$, lighting (12 h, 8:00 AM-8:00 PM, 290 lux), ventilation (10-15 times per hour), and diet (Teklad Global Diets, Harlan Laboratories Inc., Medison, WI, USA). The animal experimental procedures were approved by Korea Institute of Oriental Medicine Care and Use Committee with a reference number of \#16-010 and performed in accordance with the Korea Institute of Oriental Medicine Care Committee Guide lines.

\section{Biochemical parameters}

After sacrifice all mice, blood samples were centrifuged at 3500 rpm for $20 \mathrm{~min}$, and serum was separated. Total protein, albumin, total cholesterol, tryglyceride, urea, serum glutamic oxalate transaminase (GOT), serum glutamic pyruvate transaminase (GPT), alkaline phosphatase (ALP), and lactic dehydrogenase
(LDH) were assessed in serum using an automatic clinical chemistry analyzer XL-200 (Erba, Mannheim, Germany).

\section{Statistics}

The data were analyzed by using GraphPad Prism ver. 5.0 software (SanDiego, CA, USA). Data are presented as means \pm $\mathrm{SD}$. The significance of differences was calculated using one-way analysis of variance (ANOVA), and $p$ value of $<0.05$ was considered to indicate statistical significance.

\section{Results}

Animal survival, body weights, and relative organ weights affected by CPF

During the experiment, 10,40 , and $60 \%$ of the animals treated with 100,120 , and $150 \mathrm{mg} / \mathrm{kg}$ of CPF, respectively, died after treatment (Fig. 1B). After two days of exposure to CPF, compared with the vehicle control group, overall body weights were significantly decreased in the 120 and $150 \mathrm{mg} / \mathrm{kg}$ CPF treated groups. Among the five organs examined, the relative weights of the liver, spleen, and kidneys were significantly decreased by treatment with 100,120 , and $150 \mathrm{mg} / \mathrm{kg}$ of CPF compared with the weights of the vehicle control organs (Fig. 1C).

\section{Changes in serum biochemical parameters induced by CPF}

After sacrifice, there were statistically significant increases in GOT, GPT, ALP, and LDH activities in the serum of all CPF treated groups, except the $10 \mathrm{mg} / \mathrm{kg}$ group, compared with those of the vehicle control group (Table 2). Urea levels were increased by $\mathrm{CPF}$, except in the $120 \mathrm{mg} / \mathrm{kg}$ group, compared with the vehicle control. Based on these results, a dosage of $100 \mathrm{mg} / \mathrm{kg}$ CPF was chosen to be administered for the acute toxicity study.

\section{Effect of JGJ on CPF-induced toxicity}

After $30 \mathrm{~min}$ of treatment with $100 \mathrm{mg} / \mathrm{kg} \mathrm{CPF}, 50,100$, and 200 $\mathrm{mg} / \mathrm{kg}$ JGJ were orally administered to each respective group. As shown in Figure 2, the body and organ weights of the CPF-only control group animals were lower than those of the vehicle control group animals. On the contrary, the significant changes about the body and organ weights were not observed in $200 \mathrm{mg} / \mathrm{kg} \mathrm{JGJ}$-only treatment group. Of the five organs examined, there was almost

Table 1 Composition of Jageum-Jung (JGJ)

\begin{tabular}{|c|c|c|c|c|}
\hline No. & Scientific name & Botanical name & Amounts used (g) & Composition ratio $(\%)$ \\
\hline 1 & Rhus javanica $\mathrm{L}$. & Galla Rhois & 120 & 38.46 \\
\hline 2 & Cremastra appendiculate M. & Crenastrae Tubar & 80 & 25.64 \\
\hline 3 & Euphorbia pekinensis R. & Euphorbiae Perkinensis Radix & 60 & 19.23 \\
\hline 4 & Euphorbia lathyris L. & Euphorbiae Lathyridis Semmen & 40 & 12.82 \\
\hline 5 & Moschus moschiferus L. & Muschus & 12 & 3.85 \\
\hline \multicolumn{3}{|c|}{ Total } & 312 & 100 \\
\hline
\end{tabular}


(A)

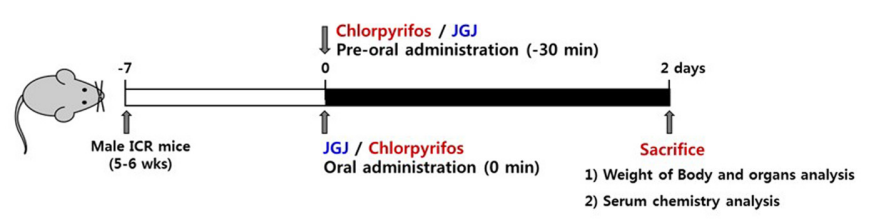

(B)

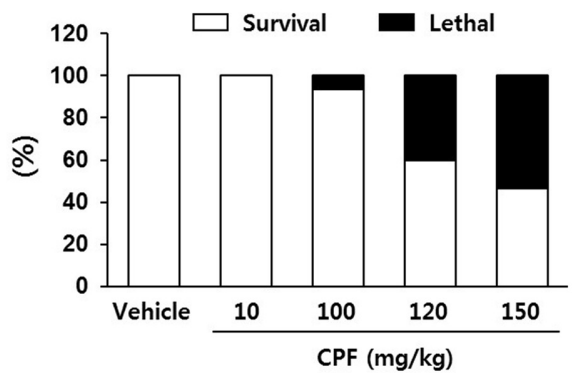

(C)
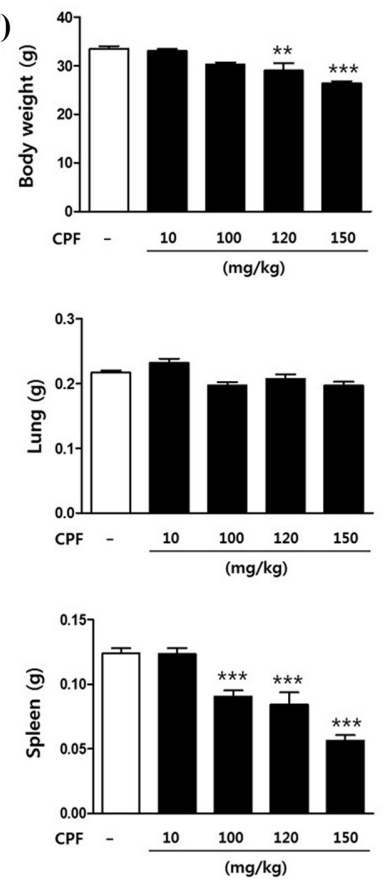
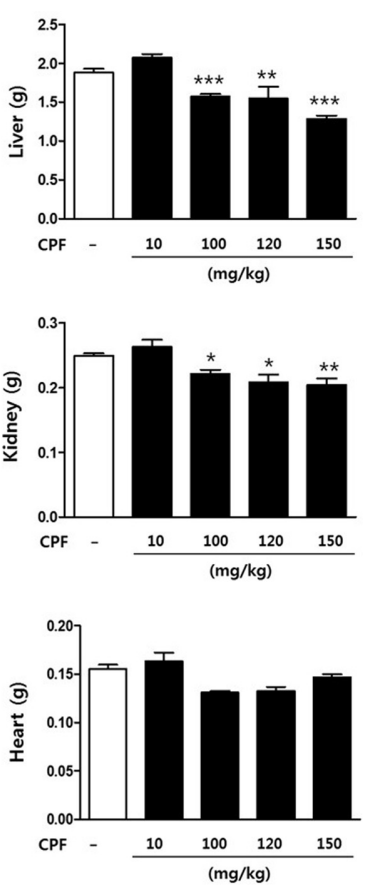

Fig. 1 Effect of acute treatment with chlorpyrifos (CPF) on the weight of the body and organs of ICR mice. (A) Experimental schedule (B) Survival rate change according to $\mathrm{CPF}$ dosage $(\mathrm{C})$ Changes in body and organ weights according to CPF dosage. The data are shown as the means \pm SD of three independent experiments. ${ }^{*} p<0.05,{ }^{* *} p<0.01$, and ${ }^{* * *} p<0.001$ versus untreated control group (vehicle only)

Table 2 Effect of acute treatment with chlorpyrifos (CPF) on serum biochemical parameters of ICR mice

\begin{tabular}{lrcccc}
\hline \hline \multirow{2}{*}{ Parameters } & \multicolumn{5}{c}{ CPF Groups } \\
\cline { 2 - 6 } & \multicolumn{1}{c}{ Vehicle } & $10 \mathrm{mg} / \mathrm{kg}$ & $100 \mathrm{mg} / \mathrm{kg}$ & $120 \mathrm{mg} / \mathrm{kg}$ & $150 \mathrm{mg} / \mathrm{kg}$ \\
\hline GOT(IU/L) & $14.20 \pm 3.259$ & $14.30 \pm 3.164$ & $27.00 \pm 3.00$ & $32.80 \pm 4.605$ & $108.9 \pm 14.854$ \\
GPT (IU/L) & $5.60 \pm 1.430$ & $6.70 \pm 2.669$ & $9.50 \pm 2.229$ & $16.60 \pm 2.045$ & $65.10 \pm 2.335$ \\
ALP (IU/L) & $23.50 \pm 8.276$ & $22.30 \pm 4.473$ & $25.67 \pm 4.243$ & $23.60 \pm 2.881$ & $22.40 \pm 3.777$ \\
LDH (IU/L) & $320.7 \pm 80.07$ & $293.4 \pm 63.48$ & $340.0 \pm 125.45$ & $331.0 \pm 275.05$ & $718.5 \pm 221.23 *$ \\
Urea (mg/dL) & $5.14 \pm 0.712$ & $6.65 \pm 0.943$ & $6.47 \pm 1.494$ & $4.44 \pm 0.385$ & $7.55 \pm 1.670$ \\
\hline
\end{tabular}

The data are shown as the means $\pm \mathrm{SD}$ of three independent experiments. ${ }^{*} p<0.05$ versus untreated control group (vehicle only). GOT, glutamic oxalate transaminase; GPT, glutamic pyruvate transaminase; ALP, alkaline phosphatase; LDH, lactic dehydrogenase

no difference in the weights of the hearts throughout the experiment. The body and organ weights loss induced by CPF treatment was slightly reversed by JGJ treatment. The decrease of lung and spleen weights induced by CPF was recovered according to JGJ concentration dependently. In particular, the loss of spleen weight induced by CPF was recovered about 7 and $14 \%$ by treatment with 100 and $200 \mathrm{mg} / \mathrm{kg} \mathrm{JGJ}$, respectively. The results of the evaluation of serum biochemical parameters are shown in Table 3. Indicators of hepatic malfunction, including GOT, GPT, ALP, LDH, total protein, and albumin activities, were decreased by treatment with JGJ. The elevated urea levels in the serum induced by CPF also decreased following JGJ administration. The levels of total cholesterol and triglycerides as lipid profiles were increased by CPF treatment compared with the vehicle control. On the other hand, these lipid profiles were decreased in JGJtreated groups compared with the CPF-only group. Triglyceride levels were markedly decreased by JGJ treatment, especially by treatment of $200 \mathrm{mg} / \mathrm{kg} \mathrm{JGJ}$.

\section{Discussion}

In agriculture, pesticides are used to achieve better quality products in greater quantities. However, they have harmful effects on human health, inducing oxidative stress and neurotoxicity [16]. $\mathrm{CPF}$, an organophosphorus insecticide, is a lipophilic molecule that can easily pass through the cell membrane into the cytoplasm $[17,18]$. Therefore, exposure to CPF can lead to the development of oxidative stress through modification of endogenous antioxidants like superoxide dismutase, glutathione peroxidase, glutathione reductase, and glutathione-S-transferase in various tissues, which causes oxidative damage and histopathological changes in the 

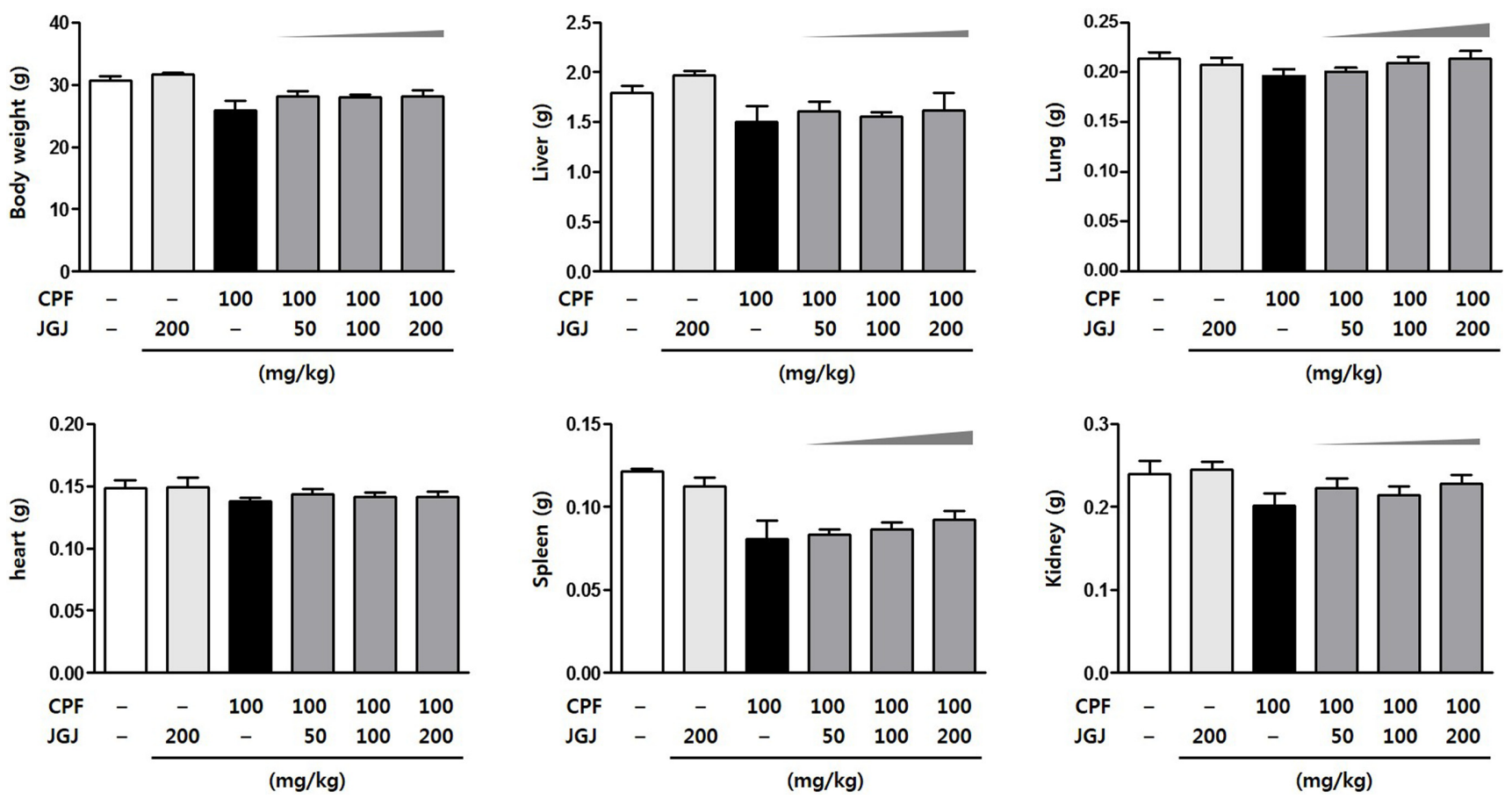

Fig. 2 Protective effect of JGJ against CPF-induced changes in body and organ weights in ICR mice. For a period of 2 days to evaluate the acute toxicity of CPF, mice received $100 \mathrm{mg} / \mathrm{kg}$ CPF in corn-oil $(150 \mu \mathrm{L})$. CPF was first exposured, and JGJ was treated thirty minuites later as a posttreatment of JGJ. Only JGJ-treated group was administrated with corn-oil $(150 \mu \mathrm{L})$ at first exposured step and administrated with $200 \mathrm{mg} / \mathrm{kg}$ at posttreatment step

Table 3 Protective effect of JGJ on serum biochemical parameters against chlorpyrifos (CPF)-induced toxicity in ICR mice

\begin{tabular}{lcccccc}
\hline \hline \multirow{2}{*}{ Parameters } & \multirow{2}{*}{ Vehicle } & JGJ 200mg/kg & CPF 100 mg/kg & \multicolumn{3}{c}{ CPF 100 mg/kg + } \\
\cline { 5 - 7 } & & & & JGJ 50 mg/kg & JGJ 100 mg/kg & JGJ 200 mg/kg \\
\hline GOT (IU/L) & $14.60 \pm 3.362$ & $13.30 \pm 1.947$ & $20.50 \pm 8.737$ & $15.80 \pm 3.633$ & $17.60 \pm 8.234$ & $15.60 \pm 5.413$ \\
GPT (IU/L) & $6.60 \pm 2.608$ & $6.30 \pm 1.418$ & $9.50 \pm 4.359$ & $6.60 \pm 1.517$ & $7.40 \pm 2.074$ & $7.20 \pm 2.950$ \\
ALP (IU/L) & $17.80 \pm 2.683$ & $20.90 \pm 3.348$ & $22.50 \pm 5.568$ & $16.00 \pm 3.808$ & $16.40 \pm 1.517$ & $21.00 \pm 8.888$ \\
LDH (IU/L) & $333.8 \pm 154.40$ & $407.4 \pm 152.43$ & $499.3 \pm 130.00$ & $421.0 \pm 120.80$ & $373.6 \pm 165.00$ & $371.4 \pm 174.60$ \\
Urea (mg/dL) & $6.66 \pm 0.847$ & $5.65 \pm 0.790$ & $8.25 \pm 3.834$ & $6.44 \pm 0.885$ & $6.54 \pm 0.871$ & $5.90 \pm 1.065$ \\
Glucose (mg/dL) & $36.00 \pm 2.550$ & $39.00 \pm 8.981$ & $27.00 \pm 13.090$ & $29.60 \pm 5.459$ & $29.20 \pm 4.658$ & $33.40 \pm 22.90$ \\
Total cholesterol (mg/dL) & $24.00 \pm 2.915$ & $27.00 \pm 4.967$ & $33.75 \pm 9.179$ & $26.00 \pm 4.000$ & $24.60 \pm 3.209$ & $29.20 \pm 9.094$ \\
Triglyceride (mg/dL) & $24.60 \pm 9.633$ & $17.10 \pm 5.587$ & $33.25 \pm 17.000$ & $18.40 \pm 8.264$ & $16.80 \pm 3.271$ & $15.20 \pm 8.701 *$ \\
Total protein (g/dL) & $1.08 \pm 0.130$ & $1.08 \pm 0.103$ & $1.20 \pm 0.163$ & $1.06 \pm 0.055$ & $1.02 \pm 0.045$ & $1.14 \pm 0.207$ \\
Albumin (g/dL) & $0.84 \pm 0.114$ & $0.82 \pm 0.079$ & $0.90 \pm 0.082$ & $0.84 \pm 0.055$ & $0.78 \pm 0.045$ & $0.84 \pm 0.152$ \\
\hline
\end{tabular}

The data are shown as the means \pm SD of three independent experiments. ${ }^{*} p<0.05$ versus CPF $100 \mathrm{mg} / \mathrm{kg}$ treated group GOT, glutamic oxalate transaminase; GPT, glutamic pyruvate transaminase; ALP, alkaline phosphatase; LDH, lactic dehydrogenase

reproductive system [5,19-21]. In particular, the antioxidant defense function in the liver is decreased following liver damage [19]. For this reason, many studies have reported evidence that some substances and molecules from natural sources can reduce the harmful effects and correct the dysfunctions induced by pesticide toxicity. Black tea water extract has a significant protective effect on the liver tissue from the oxidative stress induced by pesticides [22,23]. In addition, hepatotoxicity by pesticides such as malathion or diazinon can be reduced through treatment with ginger and vitamin E, respectively $[24,25]$. The co- administration of curcumin and vitamin $\mathrm{E}$ also prevents the oxidative damages of the lung tissues in CPF-treated rats [26].

In this study, the toxicity of chlorpyrifos and the protective effect of JGJ were investigated. McCollister et al. reported the $\mathrm{LD}_{50}$ value of CPF is between 118 and $245 \mathrm{mg} / \mathrm{kg}$ in mice [27]. Furthermore, the oral $\mathrm{LD}_{50}$ of CPF for male rats is $135 \mathrm{mg} / \mathrm{kg}$ body weight [8]. Accordingly, to induce acute CPF toxicity, we administered $150 \mathrm{mg} / \mathrm{kg}$ CPF, which is within the range of $\mathrm{LD}_{50}$ values for mice, and confirmed this to be an accurate value. Based on this result, at concentration of $100 \mathrm{mg} / \mathrm{kg} \mathrm{CPF}$, body and organ 
weights were reduced by CPF treatment, slightly recovered in JGJ administration. Especially, the treatment of JGJ markedly led to the increase of spleen weights. In acute oral toxicity study, splenic dysfunction was caused by spleen damage, which lead to the reduction of spleen weights [28]. Furthermore, splenic dysfunction is related to metabolic disorders [29]. From these evidenced reports, our results present that JGJ may affect the recovery of spleen damage induced by CPF, however, it needs the investigated study about spleen function such as determination of hematological parameters or inflammation assay to ensure these results.

In this study, biochemical parameters were also investigated in order to assess changes in hepatic function and changes in lipid profile. The activities of GOT, GPT, APL, and LDH are conventional indicators of hepatic dysfunction and hepatotoxicity [20,30]. The results of this study reveal that CPF treatment increased GOT, GPT, APL, and LDH, which may be due to hepatocyte damage and necrosis. In addition, the total cholesterol and triglyceride levels within the serum were increased during CPF exposure, which can be attributed to the effect of the pesticide on the permeability of liver cell membrane [31]. Under the same conditions, JGJ treatment reduced the CPF-induced increases in the levels of GOT, GPT, APL, LDH, total cholesterol, and triglycerides. Therefore, our results suggest that JGJ may suppress the hematotoxic effects of CPF by regulating the activities of liver enzymes and the function of hematological constituents.

JGJ consists of specific herbs which have detoxifying effects. Galla Rhois is the gall produced by the aphid, Schlechtendalia chinensis (Bell), on the leaves of Rhus chinensis, and contains about $50-90 \%$ gallotannin, which has antioxidant and hepatoprotective properties [32,33]. Cremastrae Tuber is the tuber of Cremastra appendiculata M. and contains glucomannan and colchicine, which have anti-inflammatory and anticancer properties [34,35]. Euphorbiae Pekinensis Radix is the root of Euphorbia pekinensis R. and contains anthraquinones, anthraquinone glycosides, and euphorbol, which regulate nephrotoxicity [36]. However, Euphorbiae Pekinensis Radix commonly uses the form applied the processing method for reduction of toxicity [37]. Euphorbiae Lathyridis Semen is the seed of Euphorbia lathyris L. and contains euphorbiasteroid, lathyrol diacetate nicotinate, and daphnctin, which have the antioxidant properties [38]. Muschus comes from the musk deer and contains about $0.5-2 \%$ muscone, which has antioxidant and neuroprotective properties [39]. In previous study, we identified the major constituents of consisted herbs of JGJ, including gallic acid, methylgallate, militarin, ellagic acid, 1,2,3,4,6penta- $O$-galloyl- $\beta$-D-glucose (PGG), ingenol, muscone, and eudesmin, in JGJ water extract by using a HPLC-DAD analysis [15]. Interestingly, Galla Rhois accounts for the largest percentage in JGJ composition, which makes guesses that the various gallotannins in Galla Rhois assists the hepatoprotective effect of JGJ. Therefore, our results present that the protective effect of JGJ against CPF-induced toxicity may result from the complex constituents action of JGJ in this study.
However, to build on these results, the protective effect of JGJ against chronic CPF-induced toxicity must be investigated.

Acknowledgments This work was supported by grants of Medi-city fund from Dae-gu (No. G17060) and grant from the Korea Institute of Oriental Medicine funded by the Ministry of Science and ICT, Republic of Korea (K18101)

\section{References}

1. Cetin N, Cetin E, Eraslan G, Bilgili A (2007) Chlorpyrifos induces cardiac dysfunction in rabbits. Res Vet Sci 82(3): 405-408

2. Saulsbury MD, Heyliger SO, Wang KY, Johnson DJ (2009) Chlorpyrifos induces oxidative stress in oligodendrocyte progenitor cells. Toxicology 259(1-2): 1-9

3. Sandahl JF, Baldwin DH, Jenkins JJ, Scholz NL (2005) Comparative thresholds for acetylcholinesterase inhibition and behavioral impairment in coho salmon exposed to chlorpyrifos. Environ Toxicol Chem 24(1): 136-145

4. Khan SM, Kour G (2007) Subacute oral toxicity of chlorpyriphos and protective effect of green tea extract. Pestic Biochem Phys 89(2): 118123

5. Verma RS, Mehta A, Srivastava N (2007) In vivo chlorpyrifos induced oxidative stress: Attenuation by antioxidant vitamins. Pestic Biochem Phys 88(2): 191-196

6. Uzun FG, Demir F, Kalender S, Bas H, Kalender Y (2010) Protective effect of catechin and quercetin on chlorpyrifos-induced lung toxicity in male rats. Food and Chemical Toxicology 48(6): 1714-1720

7. Demir F, Uzun FG, Durak D, Kalender Y (2011) Subacute chlorpyrifosinduced oxidative stress in rat erythrocytes and the protective effects of catechin and quercetin. Pestic Biochem Phys 99(1): 77-81

8. Goel A, Dani V, Dhawan DK (2006) Chlorpyrifos-induced alterations in the activities of carbohydrate metabolizing enzymes in rat liver: The role of zinc. Toxicology letters 163(3): 235-241

9. Rahman MF, Mahboob M, Danadevi K, Saleha Banu B, Grover P (2002) Assessment of genotoxic effects of chloropyriphos and acephate by the comet assay in mice leucocytes. Mutat Res 516(1-2): 139-147

10. Qiao D, Seidler FJ, Slotkin TA (2005) Oxidative mechanisms contributing to the developmental neurotoxicity of nicotine and chlorpyrifos. Toxicol Appl Pharmacol 206(1): 17-26

11. Zhou X, Seto SW, Chang D, Kiat H, Razmovski-Naumovski V, Chan K, Bensoussan A (2016) Synergistic Effects of Chinese Herbal Medicine: A Comprehensive Review of Methodology and Current Research. Front Pharmacol 7: 201

12. Che CT, Wang ZJ, Chow MSS, Lam CWK (2013) Herb-Herb Combination for Therapeutic Enhancement and Advancement: Theory, Practice and Future Perspectives. Molecules 18(5): 5125-5141

13. Lee MS, Ahn KS, Moon JJ (1979) A literature review on the detoxifying effect of Jakeumjung. Journal of East-West Medicine 4(3): 34-37

14. Cho Y, Jeon J, Shin Y, Seol J, Rhee Jae, Won J, Moon G (2007) Induction of Apoptosis and Cell Cycle Arrest by Jageum-Jung in HepG2 Hepatoma Cells. Korean Journal of oriental internal medicine 28(4): 694

15. Yang JH, Do HJ, Lee E, Yim NH, Cho WK, Park KI, Ma JY (2018) Jageum-Jung improves 2,4-dinitrochlorobenzene-induced atopic dermatitislike skin lesions in mice and suppresses pro-inflammatory chemokine production by inhibiting TNF-alpha/IFN-gamma-induced STAT-1 and NFkappaB signaling in HaCaT cells. J Ethnopharmacol 221: 48-55

16. Giordano G, Afsharinejad Z, Guizzetti M, Vitalone A, Kavanagh TJ, Costa LG (2007) Organophosphorus insecticides chlorpyrifos and diazinon and oxidative stress in neuronal cells in a genetic model of glutathione deficiency. Toxicol Appl Pharmacol 219(2-3): 181-189

17. Kalender Y, Kaya S, Durak D, Uzun FG, Demir F (2012) Protective 
effects of catechin and quercetin on antioxidant status, lipid peroxidation and testis-histoarchitecture induced by chlorpyrifos in male rats. Environmental toxicology and pharmacology 33(2): 141-148

18. Joshi SC, Mathur R, Gulati N (2009) Testicular toxicity of chlorpyrifos (an organophosphate pesticide) in albino rat. Toxicol Ind Health 2007, 23(7): 439-444

19. Limon-Pacheco J, Gonsebatt ME: The role of antioxidants and antioxidant-related enzymes in protective responses to environmentally induced oxidative stress. Mutat Res-Gen Tox En 674(1-2): 137-147

20. Mansour SA, Mossa ATH (2010) Oxidative damage, biochemical and histopathological alterations in rats exposed to chlorpyrifos and the antioxidant role of zinc. Pestic Biochem Phys 96(1): 14-23

21. Mehta A, Verma RS, Srivastava N (2009) Chlorpyrifos induced alterations in the levels of hydrogen peroxide, nitrate and nitrite in rat brain and liver. Pestic Biochem Phys 94(2-3): 55-59

22. Khan SM, Sobti RC, Kataria L (2005) Pesticide-induced alteration in mice hepato-oxidative status and protective effects of black tea extract. Clin Chim Acta 358(1-2): 131-138

23. Khan SM (2006) Protective effect of black tea extract on the levels of lipid peroxidation and antioxidant enzymes in liver of mice with pesticide-induced liver injury. Cell Biochem Funct 24(4): 327-332

24. Ahmed RS, Seth V, Pasha ST, Banerjee BD (2000) Influence of dietary ginger (Zingiber officinales Rosc) on oxidative stress induced by malathion in rats. Food and chemical toxicology: an international journal published for the British Industrial Biological Research Association 38(5): 443-450

25. Kalender S, Ogutcu A, Uzunhisarcikli M, Acikgoz F, Durak D, Ulusoy Y, Kalender Y (2005) Diazinon-induced hepatotoxicity and protective effect of vitamin $\mathrm{E}$ on some biochemical indices and ultrastructural changes. Toxicology 211(3): 197-206

26. Hassani S, Sepand MR, Jafari A, Jaafari J, Rezaee R, Zeinali M, Tavakoli F, Razavi-Azarkhiavi K (2015) Protective effects of curcumin and vitamin $\mathrm{E}$ against chlorpyrifos-induced lung oxidative damage. Human \& experimental toxicology 34(6): 668-676

27. McCollister SB, Kociba RJ, Humiston CG, McCollister DD (1974) Studies on the acute and long-term oral toxicity fo chlorpyrifos $(0,0$ diethyl-0(3,5,6-trichloro-2-pyridyl) phosphorothioate). Food Cosmet Toxicol 12(1): 45-61

28. Yi C, Wu MX, Jie L, Ma XJ, Shi JL, Wang SN, Zheng ZQ, Guo JY (2018) Acute and sub-acute oral toxicity studies of the aqueous extract from radix, radix with cortex and cortex of Psammosilene tunicoides in mice and rats. J Ethnopharmacol 213: 199-209

29. Xiang F, Peng L, Yin Z, Jia R, Hu Z, Li Z, Ni X, Liang X, Li L, He C (2015) Acute and subchronic toxicity as well as evaluation of safety pharmacology of Galla chinensis solution. J Ethnopharmacol 162: 181190

30. Deng Y, Zhang Y, Lu Y, Zhao Y, Ren H (2016) Hepatotoxicity and nephrotoxicity induced by the chlorpyrifos and chlorpyrifos-methyl metabolite, 3,5,6-trichloro-2-pyridinol, in orally exposed mice. Sci Total Environ 544: 507-514

31. Lasram MM, Annabi AB, El Elj N, Selmi S, Kamoun A, El-Fazaa S, Gharbi N (2009) Metabolic disorders of acute exposure to malathion in adult Wistar rats. J Hazard Mater 163(2-3): 1052-1055

32. Go J, Kim JE, Koh EK, Song SH, Kang HG, Lee YH, Kim HD, Hong JT, Hwang D (2017) Hepatoprotective Effect of Gallotannin-enriched Extract Isolated from Gall on Hydrogen Peroxide-induced Cytotoxicity in HepG2 Cells. Pharmacogn Mag 13(50): S294-S300

33. Go J, Kim JE, Koh EK, Song SH, Sung JE, Lee HA, Lee YH, Lim Y, Hong JT, Hwang DY (2016) Protective Effect of Gallotannin-Enriched Extract Isolated from Galla Rhois against CCl(4)-Induced Hepatotoxicity in ICR Mice. Nutrients 8(3): 107

34. Li S, Xue Z, Wang SJ, Yang YC, Shi JG (2008) Terpenoids from the tuber of Cremastra appendiculata. Journal of Asian Natural Products Research 10(7): 677-683

35. Liu XQ, Li XP, Yuan WK, Yuan QY, Qin BH (2016) Two New Phenanthrene Glucosides from Cremastra appendiculata and their Cytotoxic Activities. Natural product communications 11(4): 477-479

36. Kong LY, Li Y, Wu XL, Min ZD (2002) Cytotoxic diterpenoids from Euphorbia pekinensis. Planta medica 68(3): 249-252

37. Qiu Y, Yu H, Wu H, Zhu F, Tao W, Xu Q (2012) Comparative study on toxicity of Euphorbia before and after being prepared by vinegar. Zhongguo Zhong Yao Za Zhi 37(6): 796-799

38. Zhang L, Wang C, Meng Q, Tian Q, Niu Y, Niu W (2017) Phytochemicals of Euphorbia lathyris L. and Their Antioxidant Activities. Molecules 22(8): 1335

39. Xia XH, Li Q, Liu M (2014) Neuroprotective effect of a formula, moschus combined with borneolum synthcticum, from traditional chinese medicine on ischemia stroke in rats. Evidence-based complementary and alternative medicine : eCAM 2014: 157938 